\title{
Heat-protective Ventilated Jackets: A Comparison of Humid and Dry Ventilating Air
}

\author{
G. W. CROCKFORD and D. E. LEE \\ From the M.R.C. Environmental Physiology Research Unit, London School of Hygiene \\ and Tropical Medicine, London
}

A comparison has been made between humid and dry air for ventilating a heat-protective jacket. At sensible cooling capacities of $4.5 \mathrm{kcal} . / \mathrm{min}$. and above, humid and dry air provided equal protection. At sensible cooling capacities of $4 \mathrm{kcal} . / \mathrm{min}$. and above, the subject achieved thermal equilibrium within $65 \mathrm{~min}$. with both humid and dry air, but below this value humid ventilating air is associated with elevated sweat rates and a failure to achieve thermal equilibrium within 65 minutes.

In industry, there are many situations in which the thermal conditions are such that workers experience a gradual increase in body temperature and are unable to achieve thermal equilibrium. The time spent in these environments may vary from 30 minutes to an hour or so but eventually the worker has to retire and recover in a cooler environment. Such working areas, although uncomfortable to work in, do not normally warrant the use of elaborate and expensive ventilated suits and in fact the operatives are generally reluctant to accept any protective garment which necessitates taking off their own clothes. It is, however, still possible to provide a limited but useful degree of protection if the operative is prepared to wear a ventilated jacket over his vest and shirt. Such an air-ventilated jacket assembly (Fig. I) has recently been introduced in the steel industry for protecting men against low levels of heat stress. The air supply for the jacket is cooled to the wet bulb temperature by bubbling it through water in an evaporator (Crockford, Lee, and Burns, 1965). Consequently the sensible or convective cooling capacity of the air is enhanced at the expense of the insensible or evaporative cooling capacity.

The two most interesting features of the ventilated jacket are therefore its reliance on the protection of only a portion of the body surface against heat and the use of humid air for cooling the wearer. Because of the potential utility of the garment in industry it was decided that a fairly exact assessment of the protection provided by the jacket should be made

Received for publication June I I, 1966. in terms of the minimum effective flow conditions for dry and humid ventilating air.

The ventilated jacket is worn over a vest and shirt; a visor protecting the face and extensions from the jacket into the trouser legs can also be provided. In the investigation reported here the jacket was worn without a visor or extension to the legs, only the trunk being protected.

The test environment was chosen with due regard to the practical situation in the steel industry in which a high radiant heat load is often present.

\section{Materials and Procedure}

Two or three experiments were done each day on one heat-acclimatized subject in the post-absorptive state. A thermal environment of $40^{\circ} \mathrm{C}$. $\left(104^{\circ} \mathrm{F}\right.$.) and $20^{\circ} \mathrm{C}$. $\left(68^{\circ} \mathrm{F}\right.$.), dry and wet bulb respectively, with an air movement of $13.7 \mathrm{~m}$. $/ \mathrm{min}$. ( $45 \mathrm{ft}$. $/ \mathrm{min}$.) was used for each exposure. A radiant heat load was also imposed by lining the climatic chamber with hammered aluminium sheet and placing electric heater elements in each corner of the chamber. A globe temperature of $50^{\circ} \mathrm{C}$. $\left(122^{\circ} \mathrm{F}\right.$.) was achieved in the working section of the chamber, giving a mean radiant temperature of about $58^{\circ} \mathrm{C}$. $\left(136^{\circ} \mathrm{F}.\right)$.

Throughout the experiments the subject wore grey worsted flannel trousers, cotton vest, pants, shirt, woollen socks, and shoes. This clothing was weighed before and after each exposure with the towel used for wiping the subject. Over the vest and shirt the subject wore the ventilated jacket, which covered the trunk from the waist to the neck, and over it a light cotton shortsleeved jacket.

The subject. after being weighed nude to $\pm 5 \mathrm{~g}$., was fitted with four skin thermocouples, attached to the trunk with adhesive tape, and dressed. After the skin 


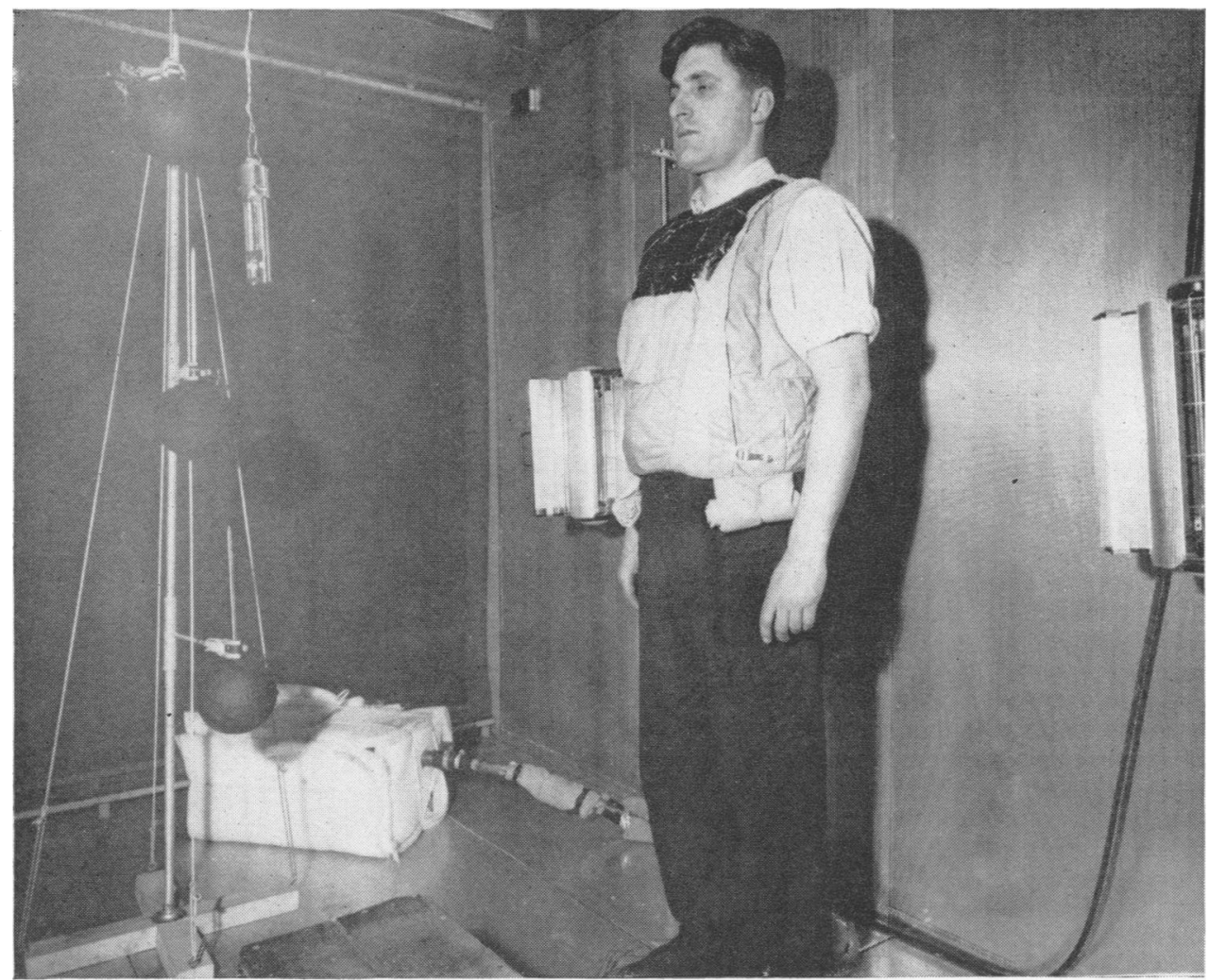

FIG. I. The ventilated jacket as used in the investigation. The diffusing panel on the front of the jacket, which normally supplies air to the face, has been blocked off so directing it all onto the trunk. The evaporative cooler, insulated in foamed plastic, is on the floor beside the subject.

and oral temperatures and the pulse rate had been recorded, the subject entered the climatic chamber where he put on the ventilated garment and stood at rest for five minutes before starting a ro-minute work period climbing a 12-inch stool 12 times a minute followed by five minutes standing at rest. This routine was repeated four times, giving a total exposure time of 65 minutes. Sub-lingual temperatures were taken at five-minute intervals throughout the exposure and the pulse rate was measured by digital palpation at the wrist for 30 seconds immediately before and after each work period.

During the rest periods skin temperatures were measured on the head, arm, forearm, hand, thigh, calf, and foot, using a thermocouple stretched across a halfinch diameter perspex tube, and at four sites on the back and chest by the attached thermocouples. The mean skin temperature was calculated by weighting the measurements according to their respective skin areas, as calculated by the method of Du Bois and Du Bois (I9I6).

On completion of the run and immediately after leaving the chamber the subject's clothing was removed and placed in a plastic bag; he was then dried and weighed. Sweat losses were made good during the recovery period between experiments.
The compressed air supply to the jacket was passed through a flowmeter and then cooled, heated, or saturated with water vapour as required. The air pressure immediately beyond the flowmeter was determined using a pizometer chamber and pressure gauge, and the measured flow rate was subsequently corrected to $760 \mathrm{~mm}$. Hg (14.7 p.s.i.). The temperature of the air was monitored as it entered the jacket and regulated manually to the required temperature. For the humid air runs air was first heated to the appropriate dry bulb temperature before going into the evaporative cooler, from which it emerged almost saturated. However, in the hose between the evaporative cooler and the jacket the air temperature always rose by $\mathrm{I}$ to $3^{\circ} \mathrm{C}$., so that the air entering the jacket had a relative humidity ranging from $67 \%$ to $95 \%$. The water content of the dry air was very low, 0.23-0.69 mg./1. (0.I-3 gr. per cu. ft.), with a range of relative humidities between 0 and $33 \%$.

The temperature of the humid air supply was somewhat difficult to control, but once the system settled down it maintained practically the same temperature for the rest of the run, and, for this reason, if the cooler stabilized just off the target temperature the run was done at the temperature obtained. The mean air 
temperature was calculated by weighting each temperature measurement according to the time separating it from the previous reading generally made after a fiveminute interval. From the mean air temperature and flow rate the sensible cooling capacity of the air was calculated with reference to a skin temperature of $35^{\circ} \mathrm{C}$. The procedure used was to multiply the measured air flow in litres/minute (V) by the density of dry air $\left(\mathrm{I} \cdot 225 \mathrm{~g}\right.$./l. at $15^{\circ} \mathrm{C}$. and $760 \mathrm{~mm}$. $\mathrm{Hg}$ (Kaye and Laby, 1959; p. 57)), the specific heat $\left(0.2403 \times 10^{-3} \mathrm{kcal} . / \mathrm{g} .1\right.$ ${ }^{\circ} \mathrm{C}$. (Kaye and Laby, 1959; p. 132)) and the difference between the skin temperature, $35^{\circ} \mathrm{C}$., and the air temperature $(\Delta t)$ as shown in equation (i). When working in Btus, equation (ii) can be used.

Cooling capacity (kcal./min.) =

$$
\mathrm{V} \times \mathrm{I} \cdot 225 \times 0.2403 \times 10^{-3} \times \Delta \mathrm{t} . . .
$$

Cooling capacity (Btu/min.) $=$

$\mathrm{V}$ (c.f.m.) $\times 0.0763 \times 0.240 \times \Delta \mathrm{t}^{\circ} \mathrm{F}$. . . (ii)

The air flow conditions required to achieve a given sensible cooling capacity can be determined by inserting a given value for air flow or $\Delta t$ in the above equations and solving for the other. A worked example is given in the Appendix (p. 59). By using different combinations of air temperature $\left(15,20,25\right.$, and $30^{\circ} \mathrm{C}$., i.e., 59, 68, 77 , and $86^{\circ} \mathrm{F}$.) and flow ( 425 to $1,7001 . / \mathrm{min}$., i.e., 15 to 60 c.f.m.) sensible cooling capacities were obtained in the range 0.5 to ro $\mathrm{kcal}$. $/ \mathrm{min}$. for the dry air and 0.5 to $8.5 \mathrm{kcal}$./min. for humid air. The wet bulb temperature of the ventilating air was determined before and after each experiment.

During the investigation the state of acclimatization of the subject was assessed periodically by doing control runs in which the subject performed the usual stepclimbing procedure but without the ventilated jacket. These 'uniformity tests' were done after the initial acclimatization and on five occasions during the study.

\section{Results}

The results of the uniformity tests are set out in the Table. The second uniformity test shows a low sweat rate but, in view of the fact that the pulse rate and oral temperature are in agreement with the

TABLE

ResUlts OF The UNIFormity Tests

\begin{tabular}{c|c|c|c}
\hline Exp. & $\begin{array}{c}\text { Sweat Rate } \\
(\text { g./min. })\end{array}$ & $\begin{array}{c}\text { Oral Temperature } \\
\left({ }^{\circ} \mathrm{C} .\right)\end{array}$ & $\begin{array}{c}\text { Pulse Rate } \\
\text { (beats/min. })\end{array}$ \\
\hline I & $11 \cdot 54$ & - & 152 \\
3 & 10.70 & 38.30 & 148 \\
18 & 12.54 & 38.35 & 152 \\
26 & 13.09 & 38.54 & 150 \\
42 & 12.84 & 37.87 & 138 \\
43 & - & 38.38 & - \\
52 & 13.72 & 37.94 & 134 \\
\hline
\end{tabular}

${ }^{1}$ Oral temperature and pulse rate were measured at the end of the fourth work period. The oral temperature obtained at this time in a 95-min. run (Exp. no. 43) is also included. values found in the other tests, it has not been taken to indicate a lack of acclimatization. Subsequent uniformity tests show sweat rates between 12.5 and $13.7 \mathrm{~g}$./min., which indicates that some further small improvement in acclimatization probably occurred during the investigation. In the 65 -minute uniformity runs in this environment when the subject was unprotected, thermal equilibrium was never achieved and on one occasion when the exposure was extended to 95 minutes the oral temperature reached $38.66^{\circ} \mathrm{C}$. and was still rising. In the unacclimatized state the oral temperature and pulse rate of this subject reached values of $39.24^{\circ} \mathrm{C}$. and 172 beats $/ \mathrm{min}$. respectively at the end of a 74 -minute exposure.

For the tests using the ventilated jacket, the oral temperatures and pulse rates measured at the end of the last work period, and the weight losses, have been plotted against the sensible cooling capacity of the ventilating air in Figs. 2, 3, and 4 respectively. Results from 50 experiments are given.

The oral temperatures when using dry air and humid air are virtually the same over the range of cooling capacities 3 to ro kcal./min. (Fig. 2); within this range there is no obvious trend towards higher temperatures as the cooling capacity decreased. At a cooling capacity of $\mathrm{I} \mathrm{kcal} / \mathrm{min}$. the oral temperature shows a marked increase towards the values obtained in the uniformity tests. In experiments involving discontinuous work it is difficult to determine when a subject has come into thermal equilibrium as each rest period is accompanied by a rapid fall in oral temperature followed by a rise at the start of the next work period. However, for this study the oral temperature was considered to have become steady if the highest temperature recorded in each of the last two work periods did not differ by more than $0.12^{\circ} \mathrm{C}$. Where a greater difference was observed, the final work temperature in Fig. 2 has been underlined. The selection of a change of $0.12^{\circ} \mathrm{C}$. or less in 20 minutes as the criterion of thermal equilibrium is purely arbitrary. The pulse rates (Fig. 3) show a similar picture to that obtained from oral temperatures with definitely higher values being reached once the cooling capacity of the air falls below $2 \mathrm{kcal}$./minute. There is again no obvious difference between experiments when using dry air or humid air.

The sweat rates obtained with dry and humid ventilating air are plotted separately in Figures $4 \mathrm{a}$ and $b$. Using the jacket with only a small degree of dry air, ventilation produces a marked drop in sweat rate from the uniformity test levels, and further increases in cooling power lower the sweat rate to about $55 \%$ of the mean for the uniformity test 


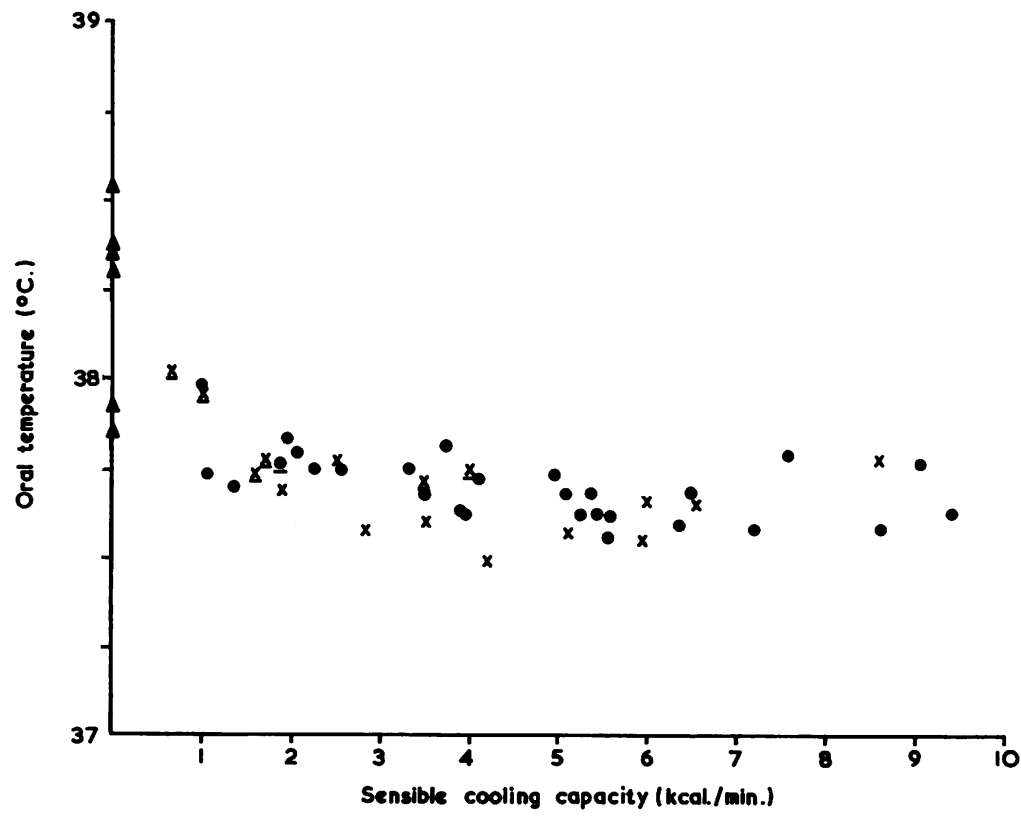

Fig. 2. The oral temperatures at the end of the last work period are plotted against the sensible cooling capacity of the ventilating air.

$[\times$ humid air; 1 dry air; $A$ uniformity results. The points underlined indicate experiments in which the maximum oral temperature in the last two work periods differed by more than $0.12^{\circ} \mathrm{C}$.]

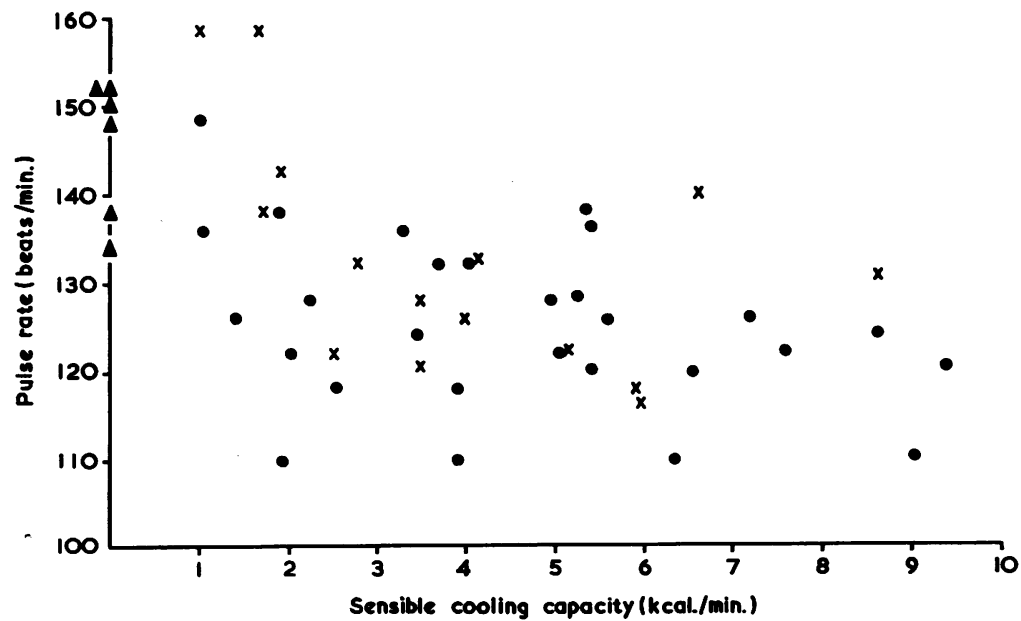

FIG. 3. The pulse rate measured immediately after the last work period is plotted against the cooling capacity of the ventilating air.

[ $\times$ humid air; dry air; $\Delta$ uniformity results] 


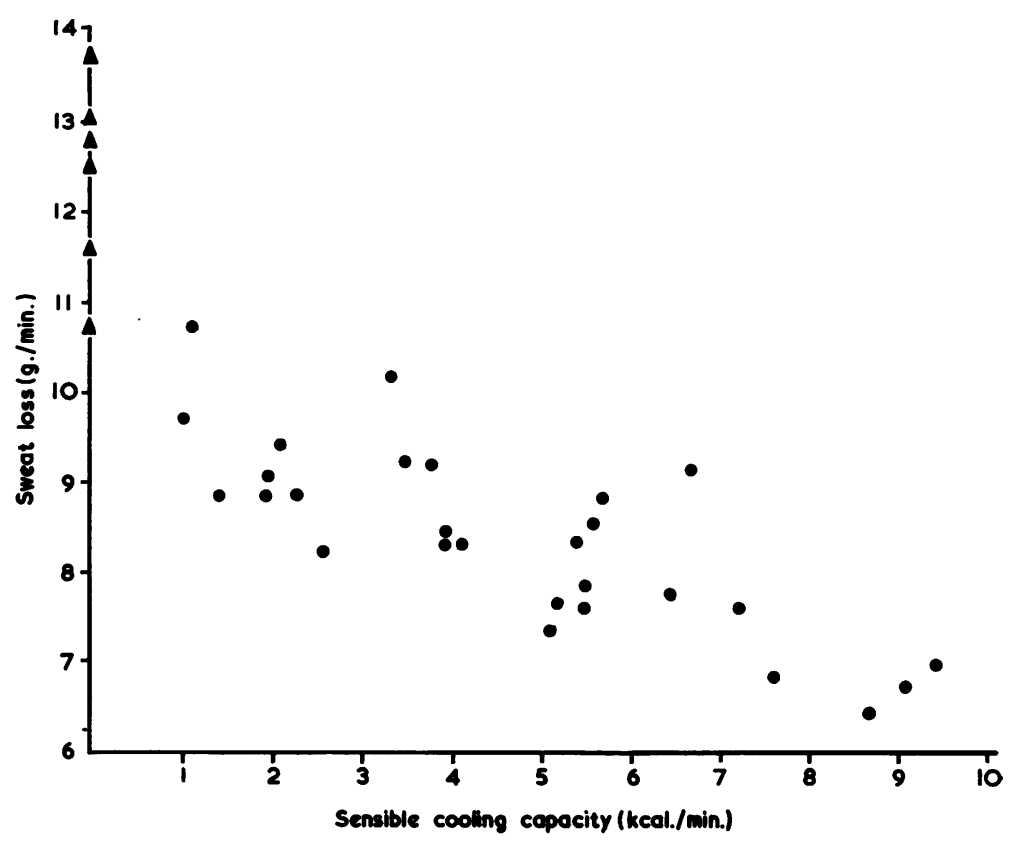

FIG. 4a. Sweat rates, obtained when the jacket was ventilated with dry air, of a number of different sensible cooling capacities. [ $\mathbf{\Delta}$ uniformity results.]

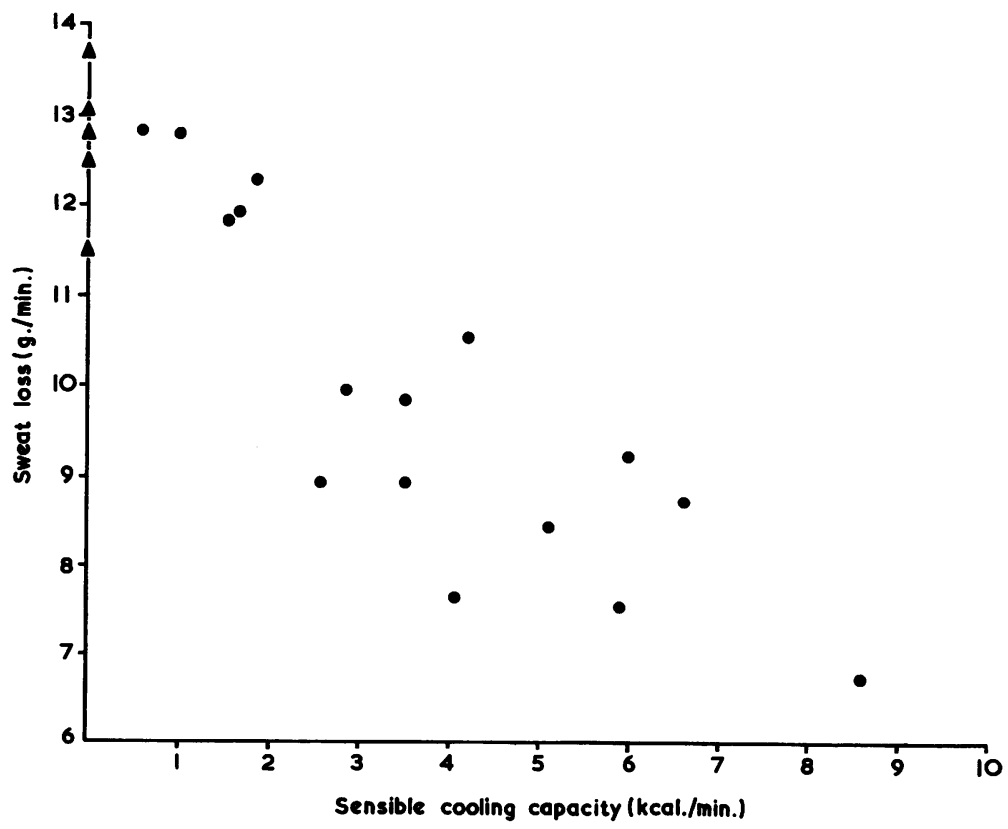

FIG. 4b. Sweat rates, obtained when the jacket was ventilated with humid air, of a number of different sensible cooling capacities. [A uniformity results.] 


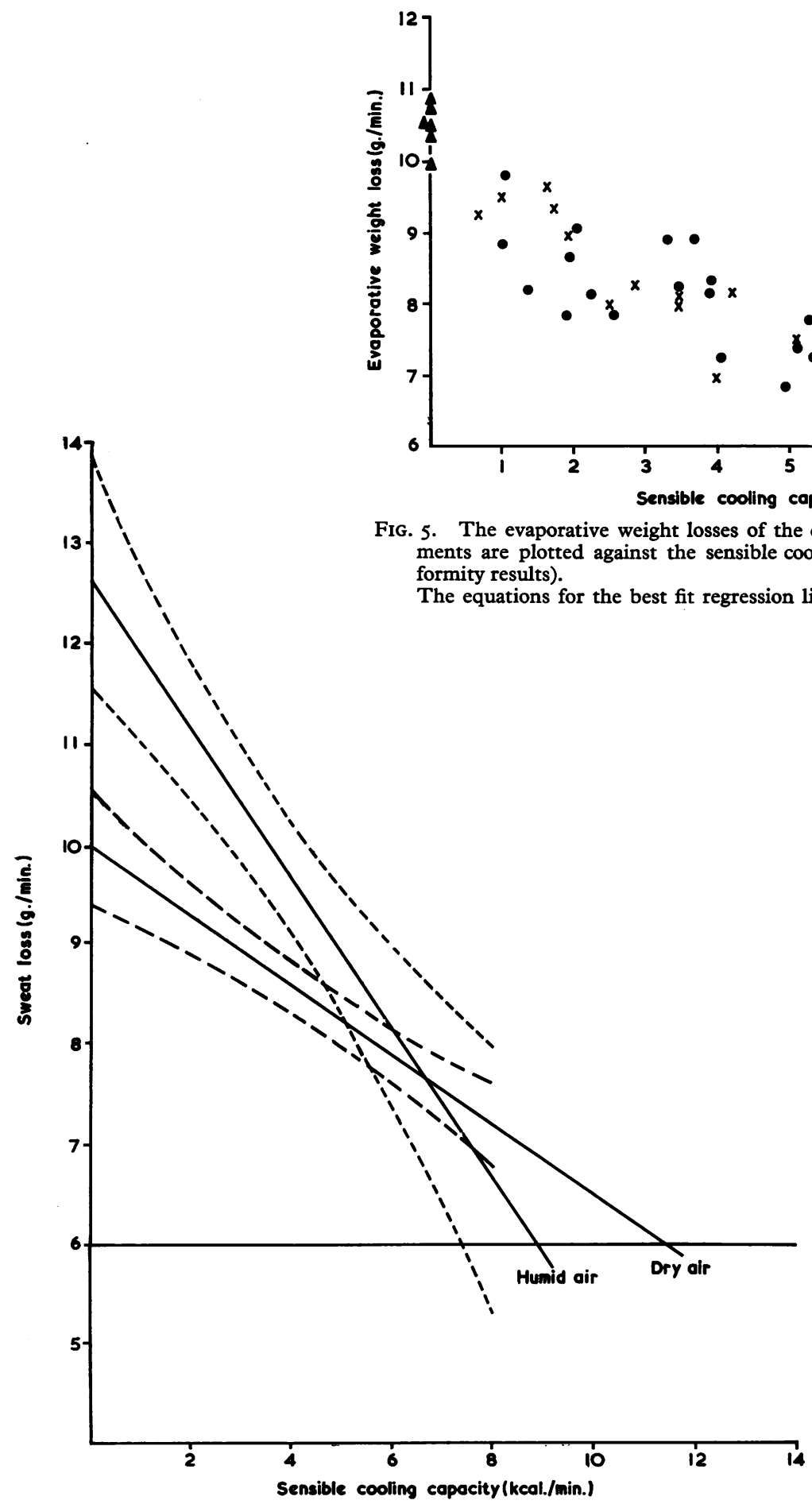

FIG. 6. The best fit regression lines for sweat loss against sensible cooling capacity of the ventilating air with $95 \%$ confidence limits fitted. 
(Fig. 4a). In the humid air runs (Fig. 4b), between cooling capacities of 9 and $3 \mathrm{kcal}$./min., values of sweat loss are obtained similar to those in the dry air tests. Below $2 \mathrm{kcal}$./min., however, there is a very marked increase in sweat rate to values 2 to $3 \mathrm{~g}$. higher than those found when using dry air. In Fig. 5 the evaporative weight loss (total sweat loss minus sweat in clothing) has been plotted against the cooling capacity of the ventilating air. The evaporative weight loss for both the dry and humid air appears to be remarkably similar, in neither case showing any marked divergence at low cooling capacities.

The best fit regression line for sweat rate $y$ as a function of cooling power $x$ is given for the dry air experiments by $y=9.9712-0.3455 x$, and for the humid air experiments by $y=12 \cdot 6784-0.7505 x$ (Fig. 6).

The regression line for the evaporative weight loss $y$ against cooling power $x$ has the form $y=$ 9.1329-0.2727x for dry air, and though the best fit for the humid air is a cubic curve, it is almost as well described by a straight line of the form $y=9.5558$ 0.38 I I $x$. Confidence limits ( $95 \%$ ) have been fitted to these lines (Fig. 6) and the sweat rates with dry and humid air can be assumed to be the same for cooling capacities of the ventilating air greater than $4.5 \mathrm{kcal}$. $/ \mathrm{min}$. with $95 \%$ confidence.

The final mean skin temperature of the unprotected part of the body was very similar in both the humid and dry air experiments, varying between $36^{\circ}$ and $37^{\circ} \mathrm{C}$. and showing no marked change with changes in cooling capacity of the ventilating air until it fell to $2.5 \mathrm{kcal}$. $/ \mathrm{min}$., when values of $37.5^{\circ} \mathrm{C}$. were registered. On the other hand, the skin protected by the jacket showed marked changes in temperature with changes in cooling capacity, the fall in skin temperature being very consistent in the humid air experiments though a considerable amount of scatter was present in the dry air experiments. The most likely explanation of this scatter is that the dry air produced very rapid local evaporation of sweat, resulting in areas of low skin temperature which could on some occasions coincide with the sites of the thermocouples. The overall effect of the ventilated jacket on the mean skin temperature was to reduce it progressively from 37 to $38^{\circ} \mathrm{C}$. found in the uniformity tests to 34 to $36^{\circ} \mathrm{C}$. as the cooling capacity of the ventilating air increased to $9 \mathrm{kcal} . / \mathrm{minute}$.

\section{Discussion}

The environment and work rate used in these tests were selected to simulate the hot conditions found in the steel industry in which men are known to work for periods of up to 40 minutes. The uniformity tests confirmed that these hot working conditions can be tolerated only for a limited time. If protective clothing is used to alleviate the thermal stress it should at least enable the wearer to achieve thermal equilibrium. The jacket does in fact enable the wearer to come into thermal equilibrium over a wide range of ventilating air flow conditions with both dry and humid air. The pattern of body temperatures in relation to the cooling capacity of the air is very similar to that found by Lind (I963) for men working within the prescriptive zone of temperatures, in that the body temperature assumed more or less the same value irrespective of the cooling capacity of the air, provided this was greater than $4 \mathrm{kcal}$./minute. At cooling capacities below $4 \mathrm{kcal} . / \mathrm{min}$. the oral temperature increased progressively as the cooling capacity decreased. A statistical curve has not been fitted to the oral temperature data as thermal equilibrium was not always attained within the 65 -minute experiment. However, visual inspection indicates that the use of humid ventilating air does not result in noticeably higher oral temperatures at the lower cooling capacities but below $4 \mathrm{kcal}$. $/ \mathrm{min}$. it does prevent the subject from coming into thermal equilibrium within 65 minutes.

Below $4 \mathrm{kcal}$. $/ \mathrm{min}$. and with humid air the subject attained thermal equilibrium within the hour on only four occasions out of 10, whereas with dry air the subject equilibrated in 12 out of 13 experiments. The pulse rates show a similar pattern to that of the oral temperatures although the increase in pulse rates does not appear until the cooling capacity has fallen to $2 \mathrm{kcal}$./minute. Below $2 \mathrm{kcal}$. $/ \mathrm{min}$. there is a rise in pulse rate which is most marked in the humid air experiments.

The oral temperature and pulse rate recordings indicate that possibly at a cooling capacity of $2 \mathrm{kcal}$./min., and certainly at $4 \mathrm{kcal} . / \mathrm{min}$., the ventilated jacket provides adequate protection in that a man is able to achieve thermal equilibrium. The data do not show a clear distinction between the protection afforded by dry and humid ventilating air, the only indication of the inferiority of humid air being provided by its failure to produce a clear indication of thermal equilibrium at cooling capacities of $4 \mathrm{kcal} . / \mathrm{min}$. and below.

The sweat rate is probably the most sensitive indicator of the thermal stress on the subject and the physiological parameter most likely to distinguish between dry and humid air. The sweat rates were, therefore, analysed statistically to determine if the humid air provided inferior protection.

Two quite different regression lines were obtained for the sweat losses in the humid and dry air experi- 
ments (Fig. 6). It should be noted that the regression line for humid air crosses that for dry air at $6.7 \mathrm{kcal} . /$ minute. This, however, is an artifact due to the lack of results for humid air at cooling capacities greater than $6.6 \mathrm{kcal}$. $/$ minute. This region was deliberately not investigated since, at the low temperatures required for such cooling capacities, humidity would have very little effect on the protection provided by the jacket. The regression line for humid air is in all probability a curve, the righthand section of which runs parallel to the dry air regression line, and then, as the cooling capacity decreases, the humidity becomes more important and the line steepens, the two regression lines becoming significantly different at $4.5 \mathrm{kcal} . / \mathrm{min}$. (95\% confidence), until at a cooling capacity of $\mathrm{I} \mathrm{kcal}$./min. or less no relief is provided by the humid air. The humidity of the ventilating air therefore appears to be of no importance unless the sensible cooling capacity is below $4.5 \mathrm{kcal}$./minute. Below this value protection is still provided, but at a value of $4 \mathrm{kcal} . / \mathrm{min}$. thermal equilibrium is no longer achieved and at I $\mathrm{kcal} . / \mathrm{min}$. the oral temperature reaches values obtained in the uniformity tests. With dry air, thermal equilibrium is attained with cooling capacities as low as I kcal./minute.

The results of this investigation therefore indicate that the humid air produced by an evaporative cooler is just as suitable as dry air for ventilating jackets provided the sensible cooling capacity of the air does not fall below $4.5 \mathrm{kcal}$./minute. When supplied with air of $4.5 \mathrm{kcal}$. $/ \mathrm{min}$. cooling capacity, or above, the jacket enabled a heat-acclimatized subject, working at about $4 \mathrm{kcal}$./min., to achieve thermal equilibrium in the hot environment used for the experiments.

The significance of the very similar evaporation losses with dry and humid air is not clear. However, the most likely explanation is that the degree of protection provided by the jacket depends on the sensible thermal capacity of the air flowing through it. At the same time the ease with which the body can dissipate the heat load by evaporation is dependent on the water vapour pressure gradient between the ventilating air and the skin. This gradient depends not only on the vapour pressure of the air but on the speed with which it is flowing from the jacket. When low air flow rates are combined with high vapour pressures difficulty is experienced in evaporating the required quantity of sweat and the wetted surface area is increased; consequently the quantity of unevaporated sweat present in the clothing increases.
The authors would like to thank Mr. S. P. Prestidge, Mr. G. C. Cashmore, and the staff of the M.R.C. Climatic Chambers, Hampstead for their technical assistance, and Mrs. A. Watts for statistical assistance.

\section{REFERENCES}

Crockford, G. W., Lee, D. E., and Burns, J. W. (1965). A laboratory trial of an evaporative cooler designed for industrial use. Brit. Iron and Steel Res. Ass. Report No. $O R / H F / 21 / 65$.

Du Bois, D., and Du Bois, E. F. (1916). Arch. intern. Med., I7, 863.

Lind, A. R. (1963). F. appl. Physiol., 18, 5 I.

Kaye, G. W. C., and Laby, T. H. (1959). Tables of Physical and Chemical Constants, 12th ed., Longmans, Green, London.

\section{Appendix}

If an assessment of a working environment indicates that the use of a ventilated jacket would alleviate the thermal stress on the operatives the minimum air flow required to achieve a cooling capacity of $4.5 \mathrm{kcal} . / \mathrm{min}$. ( $17.5 \mathrm{Btu} / \mathrm{min}$.) can be determined as follows.

The maximum water content of the compressed or ambient air, whichever is to be used for ventilating the jacket, is first determined using, for example, the wet and dry bulb temperatures of the air. The maximum dry bulb temperature of the air at the point at which it is to be used is also determined. Considering the air main as a source of ventilating air, investigation showed that it had a maximum water content of $60 \mathrm{gr} . / \mathrm{lb}$. $(8.57 \mathrm{~g} . / \mathrm{kg}$.) and that the maximum dry bulb temperature was $43 \cdot 3^{\circ} \mathrm{C}$. ( $110^{\circ} \mathrm{F}$.). The wet bulb temperature of this air is therefore $22 \cdot 5^{\circ} \mathrm{C}$. $\left(72 \cdot 75^{\circ} \mathrm{F}\right.$.) and an evaporative cooler would be expected to produce air at a relative humidity of at least $85 \%$, probably higher, giving a cooled air temperature of between $23.3^{\circ} \mathrm{C}$. and $244^{\circ} \mathrm{C}$. $\left(74^{\circ}\right.$ and $76^{\circ} \mathrm{F}$.). These figures are determined with the aid of a psychrometric chart.

From an examination of the type of work the operative was performing it was estimated that $2.4 \mathrm{~m}$. ( $8 \mathrm{ft}$.) of air hose would be required between the cooler and the operative. An allowance therefore has to be made for the rise in temperature along this hose and $0.36^{\circ} \mathrm{C} . / 30 \mathrm{~cm} .\left(0.5^{\circ} \mathrm{F}\right.$. /ft. $)$ is suggested. The maximum temperature of the ventilating air now stands at $26 \cdot 7^{\circ} \mathrm{C}$. $\left(80^{\circ} \mathrm{F}\right.$.) and, using this figure, the volume of air required can be calculated using equation (ii) as follows:-

$$
17.5 \mathrm{Btu} / \mathrm{min} .=\mathrm{V} \times 0.0763 \times 0.240 \times 15
$$$$
\mathrm{V}=64 \text { c.f.m. }
$$

The air flow required in this theoretical situation is therefore 64 c.f.m. 